\title{
APPLICATION OF THE THEORY OF CONSTRAINTS FOR PROJECT MANAGEMENT
}

\author{
Justyna Trojanowska, Ewa Dostatni \\ Poznan University of Technology, Chair of Management and Production Engineering, Poland \\ Corresponding author: \\ Justyna Trojanowska \\ Poznan University of Technology \\ Chair of Management and Production Engineering \\ Piotrowo 3, 60-965 Poznan, Poland \\ phone: $(+48) 61647-59-91$ \\ e-mail: justyna.trojanowska@put.poznan.pl
}

Received: 22 August 2016 Accepted: 27 February 2017

\begin{abstract}
The large variability of internal and external factors is a serious problem hampering production management. To meet the standards and at the same time ensure the viability of production it is necessary to quickly respond to problems that arise during production processes, and to adequately correct plans. Measures taken in the management of madetoorder production are frequently single and unique, and therefore resemble the features of project management. The paper discusses the project management method derived from the theory of constraints - CCPM. The paper describes an original algorithm for CCPM implementation and presents the results of success CCPM implementation in a company from the Wielkopolska region. The implementation of CCPM resulted in improved timeliness of order delivery, improved communication and standardization of processes related to order delivery.
\end{abstract}

KEYWORDS

project management, theory of constraints, critical chain project management.

\section{Introduction}

One of the main challenges facing SMEs in made to order manufacturing is having to combine their regular operations with continuous development, improvement and following new trends, regularly appearing in the economic environment. The pace of change taking place in the economic system, the development of techniques and technologies, changes in the law and constantly changing customer requirements mean that the failure to adapt causes obvious losses to SMEs. Global competition and market demand for customized products and services, delivered just in time, exert real stress on businesses $[1,2]$. Additionally, nowadays companies establish new manufacturing sites in different locations and form strategic relationships with business partners in order to increase their responsiveness to market changes and to share resources more effectively and efficiently [3, 4]. These factors make it even more difficult to manage the project: deliver the customer's order $[5,6]$.
Project management is a management method whose aim is to effectively reach the project objective within the specified time and a fixed budget [7]. There are many methods supporting project management described in the literature. The most commonly used in practice include Gantt chart, Critical Path Method (CPM) and Project Evaluation and Review Technique (PERT).

A Gantt chart is a horizontal bar chart developed as a production control tool in 1917 by Henry L. Gantt, an American engineer and social scientist. Frequently used in project management, a Gantt chart provides a graphical illustration of a schedule that helps to plan, coordinate, and track specific activities in a project. CPM and PERT originated in 1957 and 1958, respectively, with CPM examining the tradeoffs between project duration reduction and increases in activity and project costs; and with PERT examining the uncertainty aspects of completion dates for development projects. CPM was originally developed for use with manufacturing plant rebuilds by DuPont and PERT for use with the Polaris 
nuclear submarine program by the Special Project Office of the Department of the Navy and the consulting firm Booz Allen Hamilton [8].

These methods, however, are not always justifiable and effective due to their reliance on certain assumptions that become more questionable as projects become increasingly complex and demands for resources grow $[9,10]$.

Goldratt introduced the concept of Critical Chain Project Management for Single Project to begin to address the problems associated with the more traditional methods of PERT/CPM and Gantt charts.

Goldratt published in 1997 the concept of CCPM in the book Critical Chain [11].

The paper describes an original algorithm, developed based on in-depth analysis of the size of the time buffer, for CCPM implementation and presents case study which are the results of CCPM implementation in a company from the Wielkopolska region.

\section{Theory of constraints}

The assumptions of the TOC, as introduced by an Israeli physicist Dr. Moshe Eliyahu Goldratt, were first published in the 1984 book The Goal: Excellence In Manufacturing which offered comprehensive solutions for production management. Theory of Constraints focuses on system improvement which is defined as a series of independent processes [12, 13]. Application of the principles of TOC in practice requires a holistic view of the entire production system [14]. One of the three principles of TOC is concentration [15], i.e. focus on the most important issues. It means that all processes and positions should be supervised, although the non-critical may enjoy a certain autonomy. Most attention should be given to tasks that are crucial from the point of view of the system as a whole. The main aim of every company is to increase the profit. According to this point of view, constraints are the main obstacles in achieving the aims of companies. In other words, anything that gets in the way of gaining more profit is considered a constraint [11]. The identification of the constraint is the basis for improving the production system. According to TOC the system consists of five steps. The steps are sequential and instruct concentration of efforts on the system component that is capable of producing the most positive impact on the system [16].

The process of ongoing improvement in TOC is shown in Fig. 1.

The first step in the process of continuous improvement involves the identification and precise in- dication of the system component which hampers its global performance. According to TOC the introduction of changes must start from such a weak link, because improving other elements in the system and improvement of local efficiency will not affect the performance of the system as a whole. Each system has at least one constraint [18], and its identification is necessary for proper management [19].

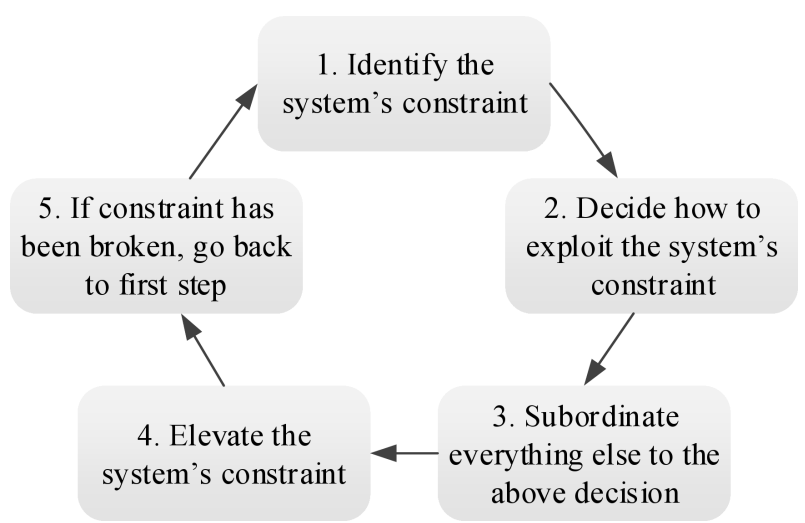

Fig. 1. Process of ongoing improvement. Source: Own study based on [17].

The second step consists in the exploitation of the constraint: the change agent should obtain as much capability as possible from the constraining component. Each lost minute caused by the fact that the constraint is not working is a loss which cannot be recovered. Therefore, in this step the change agent should take the necessary action to ensure uninterrupted work of the constraint, in order to achieve maximum capability of the system constraint.

The third step involves subordination of everything else to the decision that was made, i.e. the adjustment of the pace of work of other system elements to the pace of work of the constraint. Otherwise, when other system elements will produce faster or produce more, the cost of production will grow, among others by the increase in work-in-progress inventory.

Steps 2 and 3 are very important in the TOC, because they contribute to the structuring of the system. There are still many other ways to increase throughput and improve the system. In the fourth step, described as increasing the productivity of the constraint, TOC allows for investments which will contribute to improving the efficiency of the entire system by strengthening the constraint. If the constraint is overcome, which should happen as a result of the continuous improvement of performance as a result of step 4, it is necessary to find another component which restricts the capability of the production system. 
Appropriate identification of constraints offers many opportunities for business improvement and it positively affects the performance indicators. Note that TOC was designed as a tool for managing constraints, and it is not synonymous with continuous liquidation. At the appropriate moment, it is necessary to purposefully leave the constraint in the company, and then, through proper management thereof, control the bottleneck of the production system.

\section{CCPM}

A method of project management called Critical Chain Project Management (CCPM) was developed on the foundations of TOC. Critical Chain means that all the co-dependent tasks must take the longest path to complete, taking into account the constraints of system elements [20]. CCPM consists in planning, scheduling and maintaining the critical chain during the project in order to maximize the working time of the bottleneck, and to efficiently determine inventories for the fundamental steps of the project [21]. CCPM takes into account the ambitious task performance times and eliminates individual safety margins, adding a time buffer at the end of the project, which allows for smooth management and evaluation of project progress.

The main goal of using CCPM method is to reduce the duration or guarantee hitting the due date. The critical chain is defined as the longest chain of activities which determines overall project duration, considering both precedence and resource dependencies [11].

Watson [22] mentioned that in project environment activity duration varies depending on the availability of materials, workers, tools and in some cases the weather. Steyn [23] acknowledges that in a project some activities will be completed earlier than expected, others later. When activities are combined in a network, however, the early activities and late activities do not average out: in general, it is only the late activities that impact the project completion, which is one reason why projects tend to take longer than estimated. Due to such type of nature of project environment completion time of activities cannot be estimated with precision [24].

That is why CCPM uses time buffers in project management and provides a simple tool for monitoring projects and setting realistic deadlines [25].

The Project Buffer protects the promised due date from variation in the critical chain. Feeding Buffers protect the ability of the critical chain to maintain its relay race performance by buffering the variation of non-critical tasks and chains where they feed into or merge with critical chain tasks. With a properly sized feeding buffer inserted, the critical chain task that relies inputs from that non-critical chain has an improved chance of being able to start as soon as it predecessor critical task is complete [26].

Appropriate sizing of the buffers and proper management thereof is key to effective project management. In the traditional approach to project management safety margins are added to each project activity. There are three mechanisms of estimating the size of the safety margins [27]:

- a reference to negative experiences of the past,

- adding a separate safety margin at every level of management,

- protection against standard margin shortening by the superior by a certain percentage, by always adding such amount of time.

Analysis of the literature proves that various authors have a slightly different approach to the method of time buffer sizing.

Goldratt [11] suggested a method for sizing the buffers which was based on using $50 \%$ of the safe estimates as task duration. Having determined the critical chain, a half of the total of the critical (feeding) tasks will be used as project (feeding) buffer. The method applies the principle of aggregation to project schedule risks. Contingency reserves for individual activities are reduced so that activity durations are challenging but realistic.

Geekie [28] proposes that the buffer size of the project should be calculated as half the duration of the longest buffer feed path. Leach [29] adds that the project buffer should not be shorter than $25 \%$ of the critical chain, and that particular attention is necessary if the path is shorter than ten actions or if one action constitutes over $20 \%$ of the path duration. Łopatowska [30], in turn, claims that the project buffer should account for $50 \%$ of the difference between the time of critical chain tasks at 80 $90 \%$ task time estimate, and the time of critical chain at $50 \%$ time estimate. At the same time, it is assumed that the project buffer may not be shorter than $25 \%$ of the duration of the critical chain.

\section{Practical implementation of CCPM}

\section{Background}

The company where CCPM was implemented is a micro-company established in 1985. For 7 years it has sold made to order wooden houses. Their offer includes designing the house according to customer requirements, manufacturing the necessary house parts, transport and assembly on the customer's construction site, as well as weatherproof- 
ing and maintenance. Their sales office is in Poznań, a warehouse of finished products is located near Poznań, and parts are manufactured by one of the three suppliers in Estonia, as schematically shown in Fig. 2. Raw materials are ordered with two independent timber yards, also located in Estonia.

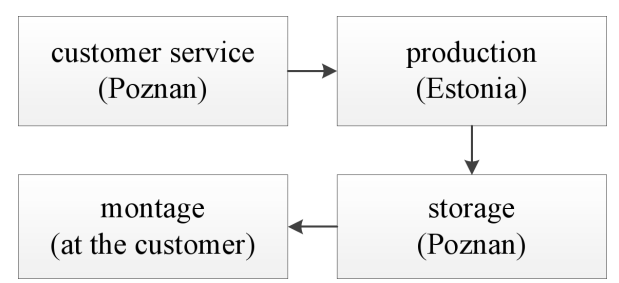

Fig. 2. Diagram of the enterprise. Own study.

The houses sold by the company are made in the "tongue and groove" technology. It is a timber joint where two elements are fitted together by inserting the "tongue" of one element into the "groove" of the other element. The technology maximizes the natural durability of the structure. Such joints ensure air- and leak-tightness and improve the stability of the building. Unlike in traditional wooden buildings with round logs, the use of the "tongue and groove" technology eliminates the negative effects of an external factor - moisture.

Project completion, or the delivery of customer order, consists of fourteen tasks divided into three stages which involve different resources. The tasks completed in the three stages are shown in Tables 1 to 3 .

The first stage is carried out in the customer service office in Poznań (Table 1).

The second stage is associated with production in Estonia (Table 2).

The third stage is the order delivery, i.e. the assembly of the house on the customer's site (Table 3).

Table 4 presents a list of all task times before the introduction of modifications, as well as the dates of task completion in a selected project carried out in 2015. To emphasize the waste of time resulting from the use of safety time margins the time buffers are listed as separate tasks.

Table 1

Tasks carried out in the first stage.

\begin{tabular}{c|l}
\hline Task no. & \multicolumn{1}{c}{ Task description } \\
\hline 1 & Discussion about order details and drafting the contract for the customer \\
\hline 2 & Preparation of detailed design documents and drawings for the producer \\
\hline 3 & Approval of the project by the customer \\
\hline 4 & Defining the detailed budget (for the purposes of the company) \\
\hline 5 & Creating a roadmap (for the purposes of the company) \\
\hline 6 & Ordering raw material with the supplier in Estonia \\
\hline 7 & Sending manufacturing order to the production plant in Estonia \\
\hline
\end{tabular}

Table 2

Tasks carried out in the second stage.

\begin{tabular}{c|l}
\hline Task no. & \multicolumn{1}{|c}{ Task description } \\
\hline 8 & Production of house parts by a supplier in Estonia \\
\hline 9 & $\begin{array}{l}\text { Packing and preparation for transport (performed in the warehouse of the manufacturer upon the request } \\
\text { of the ordering company) }\end{array}$ \\
\hline 10 & $\begin{array}{l}\text { Transport from the manufacturer to the warehouse near Poznań, carried out by an external transport } \\
\text { company }\end{array}$ \\
\hline
\end{tabular}

Table 3

Tasks carried out in the third stage.

\begin{tabular}{c|l}
\hline Task no. & \multicolumn{1}{c}{ Task description } \\
\hline 11 & $\begin{array}{l}\text { Transport of house parts from the warehouse near Poznań to the customer's site carried out by an external } \\
\text { transport company }\end{array}$ \\
\hline 12 & Organizing the assembly team and their arrival to the construction site \\
\hline 13 & Building the house and additional tasks, e.g. additional weatherproofing of the house \\
\hline 14 & Signing of the delivery-acceptance act by the customer \\
\hline
\end{tabular}


Table 4

Lead time for each task in the project.

\begin{tabular}{|c|c|c|c|c|}
\hline Item no. & Task no. & Time $[\mathrm{h}]$ & Start date & Completed date \\
\hline 1 & 1 & 4 & $01 / 09 / 15$ & $01 / 09 / 15$ \\
\hline 2 & 1 & 2 & 01/09/15 & 01/09/15 \\
\hline 3 & 2 & 8 & $01 / 09 / 15$ & $02 / 09 / 15$ \\
\hline 4 & 2 & 3 & $02 / 09 / 15$ & $03 / 09 / 15$ \\
\hline 5 & 3 & 2 & 03/09/15 & 03/09/15 \\
\hline 6 & 3 & 8 & $03 / 09 / 15$ & $04 / 09 / 15$ \\
\hline 7 & 4 & 4 & $04 / 09 / 15$ & $07 / 09 / 15$ \\
\hline 8 & 4 & 2 & $07 / 09 / 15$ & $07 / 09 / 15$ \\
\hline 9 & 5 & 2 & $07 / 09 / 15$ & $07 / 09 / 15$ \\
\hline 10 & 5 & 1 & $07 / 09 / 15$ & $07 / 09 / 15$ \\
\hline 11 & 6 & 1 & $07 / 09 / 15$ & $07 / 09 / 15$ \\
\hline 12 & 7 & 1 & $07 / 09 / 15$ & $07 / 09 / 15$ \\
\hline 13 & 7 & 1 & $07 / 09 / 15$ & $07 / 09 / 15$ \\
\hline 14 & 8 & 112 & $08 / 09 / 15$ & $25 / 09 / 15$ \\
\hline 15 & 8 & 56 & $28 / 10 / 15$ & $06 / 10 / 15$ \\
\hline 16 & 9 & 6 & $07 / 10 / 15$ & $07 / 10 / 15$ \\
\hline 17 & 9 & 2 & $07 / 10 / 15$ & $07 / 10 / 15$ \\
\hline 18 & 10 & 48 & $08 / 10 / 15$ & $09 / 10 / 15$ \\
\hline 19 & 10 & 24 & $10 / 10 / 15$ & $10 / 10 / 15$ \\
\hline 20 & 11 & 48 & $12 / 10 / 15$ & $13 / 10 / 15$ \\
\hline 21 & 11 & 24 & $14 / 10 / 15$ & $14 / 10 / 15$ \\
\hline 22 & 12 & 48 & $13 / 10 / 15$ & $14 / 10 / 15$ \\
\hline 23 & 13 & 40 & $15 / 10 / 15$ & $21 / 10 / 15$ \\
\hline 24 & 13 & 40 & $22 / 10 / 15$ & $28 / 10 / 15$ \\
\hline 25 & 14 & 2 & $28 / 10 / 15$ & $28 / 10 / 15$ \\
\hline 26 & 14 & 3 & $29 / 10 / 15$ & $29 / 10 / 15$ \\
\hline
\end{tabular}

Tasks carried out in the first stage, in the customer service office, are relatively short. The size of safety time margins (tasks number 2, 4, 6, 8, 10 and 13) results from the experience of the workers, who emphasized during the study that due to various customer requirements and the nature of cooperation with the customer it is difficult to precisely determine the duration of each task in the stage; therefore, just in case they assume adequate safety margins. Task no. 6, ordering raw material with the supplier in Estonia, is not assigned with additional safety margin, because the computer software used by the company makes it an easy task completed electronically, and the time necessary to perform the task includes potential difficulties with using the software.

Tasks carried out in the second stage are performed by subcontractors. Task no. 8, production of house parts, according to the schedule should be completed within 112 hours. However, the duration of this task is as many as 18 days because the supplier in Estonia works 5 days a week in a single shift operation only. Additionally, the task has a 50\% safety margin, which allows the analyzed company to pro- tect the deadline for project completion notified to the customer in case of any delays, which sometimes occur with the foreign supplier. $50 \%$ safety margin is assigned also to task no. 10, transport from the manufacturer in Estonia to the warehouse near Poznań. This is due to the fact that the parts are transported by one driver who has to go approximately $1300 \mathrm{~km}$. Safety time margin is used during extended wait time at the border or other unforeseen road events.

The tasks performed in the third stage are associated with the assembly of the house on the customer's site. Tasks number 11 and 12 - transport of house parts from the warehouse near Poznan to the customer's site, and arrival of the assembly team to the construction site, respectively, are performed at the same time. The time for task completion given in the table (48 hours) does not refer to the actual, physical duration of the task, but the time within which an external contractor agreed to deliver the parts within the territory of Poland. Task number 13, building the house, is scheduled to take 40 hours, or five working days. However, due to technical and organizational problems occurring during the assem- 
bly, the company assumes a 40-hour safety margin to be sure to meet the deadline agreed with the customer.

\section{Algorithm}

The present subchapter presents authors' algorithm of Critical Chain Project Management implementation (Fig. 3).

\begin{tabular}{|c|c|}
\hline 1 & Selection of a group of projects to be analyzed \\
\hline \multicolumn{2}{|r|}{$\downarrow$} \\
\hline 2 & Status quo evaluation \\
\hline \multicolumn{2}{|r|}{$\downarrow$} \\
\hline 3 & Analysis of disruptions and causes of delays \\
\hline \multicolumn{2}{|r|}{$\downarrow$} \\
\hline 4 & Identification of the critical chain \\
\hline \multicolumn{2}{|r|}{$\downarrow$} \\
\hline 5 & $\begin{array}{l}\text { Identification of task times, buffer sizes and } \\
\text { persons in charge }\end{array}$ \\
\hline \multicolumn{2}{|r|}{ 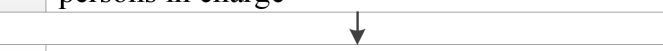 } \\
\hline 6 & $\begin{array}{l}\text { Establishing the procedure of the transfer of } \\
\text { information }\end{array}$ \\
\hline
\end{tabular}

Fig. 3. Algorithm of CCPM implementation. Own study.

The first step in the algorithm is to select the projects to be analyzed. In this study, the studied company performs one type of project: the construction of a house. Therefore the analysis focused on 7 house designs which differed due to customer requirements.

The second step involves the analysis of the status quo: the comparison of the sequence of tasks and the duration of tasks in the analyzed group of projects.

The third step of the algorithm consists in the analysis of disruptions and delays occurring during project implementation.

Step four involves the identification of the chain of critical tasks and tasks that feed into the critical chain.

In the fifth step it is necessary to determine the duration of all tasks, the size of feeding buffers and project buffer, and the persons responsible for each task.

The final step of the algorithm is to identify the procedure of the transfer of information, which is aimed at developing the relay race effect (full kit). Full kitting is completed prior to the release of a project, and its aim is to clarify requirements, getting sign offs and staging of materials. It is important to distinguish between full kitting and actually doing the tasks [5]: activities that allow project tasks to be done without interruptions are included in the full kit list, whereas activities that directly progress the tasks are excluded.

\section{The implementation of CCPM}

The implementation of CCPM in the studied company began from selecting a group of projects to be analyzed and from evaluating the status quo. Disruptions were identified and the research team discussed the causes and possible means of elimination of the disruptions. Next, the critical chain was identified. It consisted of tasks listed in Tables 1-3, excluding tasks number 4 and 5 . Due to the nature of the project the feeding branches were not identified. Then, the duration of all tasks was determined again, and persons in charge of the tasks were indentified.

As a result of the research it was decided to reduce the duration of tasks in the first stage by approximately $50 \%$. The analysis showed that task 1 is usually completed within $3-4$ hours. Therefore, it was decided to set the duration of the task as $3 \mathrm{~h}$; if necessary, the project buffer may be used. Similar conclusions were drawn from the analysis of duration of other tasks in the first stage. Task 3 was shortened significantly: the original time needed for task completion $(10 \mathrm{~h})$ resulted from the fact that the customer's visit was arranged only after the preparation of documents. After the changes, the date and time of the customer's visit is determined already during the first meeting, which further motivates employees to complete task 2 in the shortest possible time. Reducing the time needed to complete the tasks saved $6 \mathrm{~h}$. This was possible thanks to the standardization of office work in the first stage of the project. The total time of $17 \mathrm{~h}$ of buffer margins was reduced by half and transferred to the project buffer. New times for the completion of tasks in the first stage are given in Table 5.

Table 5

Task duration in the first stage.

\begin{tabular}{|c|c|c|c|}
\hline Task number & \multicolumn{2}{|c|}{ Old structure of time [h] } & New time \\
\hline 1 & 4 & 2 & $3 \mathrm{~h}$ \\
\hline 2 & 8 & 3 & $5 \mathrm{~h}$ \\
\hline 3 & 2 & 8 & $2 \mathrm{~h}$ \\
\hline 4 & 4 & 2 & $3 \mathrm{~h}$ \\
\hline 5 & \begin{tabular}{|l|l|}
2 & 1 \\
\end{tabular} & & $1.5 \mathrm{~h}$ \\
\hline 6 & 1 & & $0.5 \mathrm{~h}$ \\
\hline 7 & \begin{tabular}{|l|l|}
1 & 1 \\
\end{tabular} & & $1 \mathrm{~h}$ \\
\hline Legend: $\frac{1}{1}$ & $\begin{array}{l}\text { xpected time } \\
\text { Targin of safet }\end{array}$ & or the task & \\
\hline
\end{tabular}

Also the duration of the second stage of the project was reduced (see Table 6 ). Since all the tasks 
Management and Production Engineering Review

in the second stage are performed by a supplier, it was decided to use a feeding buffer; the buffer was created using the time saved from safety buffers protecting the deadlines of tasks in the second stage of the project. The feeding buffer was set at $50 \%$ of all safety margins used in this stage.

Table 6

Task duration in the second stage.

\begin{tabular}{|c|c|c|c|}
\hline Task number & \multicolumn{2}{|c|}{ Old structure of time [h] } & New time \\
\hline 8 & 112 & 56 & $112 \mathrm{~h}$ \\
\hline 9 & \begin{tabular}{l|l}
6 & 2
\end{tabular} & & $6 \mathrm{~h}$ \\
\hline 10 & 48 & & $48 \mathrm{~h}$ \\
\hline
\end{tabular}

$41 \mathrm{~h}$ feeding buffer was added at the end of second part of project

Safety margins assigned to tasks in the third stage were also eliminated. New time for the completion of tasks in the third stage are given in Table 7.

Table 7

Task duration in the third stage.

\begin{tabular}{c|cc|c}
\hline Task number & \multicolumn{2}{|c|}{ Old structure of time $[\mathrm{h}]$} & New time \\
\hline 11 & \multicolumn{2}{|c|}{48} & 24 \\
\hline 12 & 48 & $48 \mathrm{~h}$ \\
\hline 13 & 40 & 40 & $48 \mathrm{~h}$ \\
\hline 14 & 23 & $40 \mathrm{~h}$ \\
\hline & \multicolumn{2}{|c|}{40} & $2 \mathrm{~h}$ \\
\hline
\end{tabular}

In the third stage the original size of safety buffers was 67 hours. The time was reduced by $50 \%$ and assigned to the project buffer.

During the final stage of CCPM implementation the information transfer procedure was established to induce the so-called relay race effect. According to the procedure, the person in charge of the task which is nearly completed is obliged to notify the person in charge of the next task to prepare to work.

\section{Discussion}

The use of safety buffers caused many complications and significantly extended order delivery. It often happened that finished products were stored in the warehouse longer than necessary. Parts which had been produced sooner than expected waited to be collected from the warehouse in accordance with the original schedule, even though they could have already been transported to the construction site. Additionally, lack of contact with external shipping companies caused misunderstandings and project delays.

The introduction of CCPM allowed for the shortening of lead time and improved the timeliness of services provided.
Detailed analysis of time savings is shown in Table 8 .

Table 8

The structure of time saved.

\begin{tabular}{l|c|c|c}
\hline & Stage I & Stage II & Stage III \\
\hline Original time & $39 \mathrm{~h}$ & $248 \mathrm{~h}$ & $205 \mathrm{~h}$ \\
\hline New time & $17 \mathrm{~h}$ & $166 \mathrm{~h}$ & $138 \mathrm{~h}$ \\
\hline Project buffer & $8.5 \mathrm{~h}$ & - & $33.5 \mathrm{~h}$ \\
\hline Feeding buffer & - & $41 \mathrm{~h}$ & - \\
\hline Reduced time & $14.5 \mathrm{~h}$ & $41 \mathrm{~h}$ & $33.5 \mathrm{~h}$ \\
\hline
\end{tabular}

Table 8 shows the time for the various stages of the project before the changes were made, and the division of time to the new duration of the task, the feeding buffer, the project buffer and the total time saved as a result of the improvements.

The elimination of safety margins and the transfer of time saved to project buffer allowed the company to save at least $89 \mathrm{~h}$ (Fig. 4).

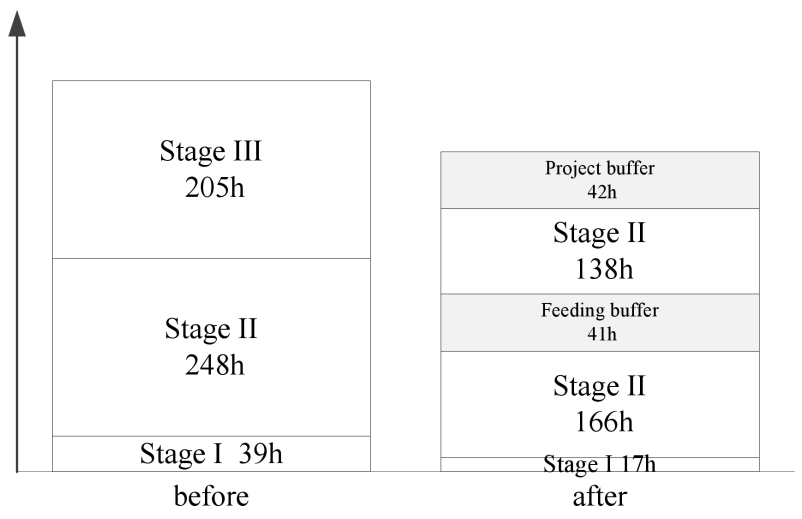

Fig. 4. Time saved. Own study.

Note, that the actual time saved ranges from 89 to 172 hours. The difference in the estimates of time saved results from the use of the feeding buffers and the project buffer, the use of which is not obligatory. In an extreme case, with no disruptions, it is possible to save as many as 172 hours. If there are some delays and it is necessary to use both buffers, $89 \mathrm{~h}$ will be saved. Due to disruptions and thanks to the introduction of the relay race effect, the time savings in the delivery of each project will range from 89 to 172 hours.

The first two projects performed in accordance with the new procedures were completed in 343 hours and 336 hours, respectively, which meant that 149 hours and 156 hours were saved, respectively.

Project management in this company should be further improved by monitoring the use of the feeding buffer and the project buffer over a longer period of time, and analyzing the buffer sizes according to the principles of buffer management. 


\section{Conclusions}

The implementation of CCPM helped the company to systematize the process of project management and improve communication within the company and between the company and its cooperators. The research also contributed to the simplification of documents used in the company, which in turn facilitated office processes.

The implementation of CCPM improved the timeliness of order delivery and the quality of service, which translates into increased customer satisfaction.

The use of CCPM results in significant improvement in project timeliness but it also requires discipline and change in the habits of employees. Overcoming the resistance to change and changing the habits of employees is the greatest challenge in CCPM implementation. Understandably, each employee tries to protect their safe time for task completion. Nevertheless, the resistance may be overcome through trainings which show that changes in the company should be viewed globally, and which emphasize the benefits from the relay race effect. CCPM is a method which brings results immediately after the first application, which additionally positively affects all project members.

A key factor in achieving satisfactory results of CCPM implementation is the proper implementation of the fifth step of the presented algorithm. To adequately determine task time and buffer sizes it is necessary to make decisions based not only on diagnostic tests, but also on actual capacities. At this stage of CCPM implementation it is crucial to use the knowledge of experienced experts and to be able to foresee undesirable behaviors which may adversely affect project delivery date. Due to the large number of criteria to be considered in each project management, it is recommended that methods supporting decision-making be used. The effectiveness of engineering tools that support decision-making has been proven in numerous publications [31-38]. Decision-making support tools enable project managers to monitor and control the key factors influencing e.g. task time, which positively affects the results of CCPM implementation.

\section{References}

[1] Santos A.S., Varela M.L.R., Putnik G.D., Alternative Approaches Analysis for Scheduling in an Extended Manufacturing Environment, IEEE Conference: 6th World Congress on Nature and Biologically Inspired Computing (NaBIC 2014), pp. 97-102, 2014.
[2] Vieira G., Reis L., Varela M.L.R., Machado J., Trojanowska J., Integrated Platform for Real-time Control and Production and Productivity Monitoring and Analysis, Romanian Review Precision Mechanics, Optics and Mechatronics, 50, 119-127, 2016.

[3] Varela M.L.R., Putnik G.D., Technologies Integration for Distributed Manufacturing Scheduling in a Virtual Enterprise, [in:] 1st International Conference on Virtual and Networked Organizations Emergent Technologies and Tools (ViNOrg 2011), Communications in Computer and Information Science, Putnik, GD; Cruz-Cunha, MM [Ed.], 248, 337347, 2012.

[4] Kujawińska A., Vogt K., Wachowiak F., Ergonomics as Significant Factor of Sustainable Production, [in:] Technology management for sustainable production and logistics, Golinska P., Kawa A. [Eds.], pp. 193203, 2015, DOI: 10.1007/978-3-642-33935-6_10.

[5] Weiss Z., Diakun J., Dostatni E., Design management in virtual intranet environment, [in:] International Conference on Cybernetics and Information Technologies, Systems and Applications and 10th International Conference on Information Systems Analysis and Synthesis, Aguilar J., Ferrer J., et al. [Eds.], Orlando, Vol. 3, Proceedings, pp. 253-256, 2004.

[6] Sabahudin J., Diering M., Brdarevic S., Opinions of the consultants and certification houses regarding the quality factors and achieved effects of the introduced quality system, Tehnicki Vjesnik-Technical Gazette, 19, 2, 211-220, 2012.

[7] A Guide to the Project Management Body of Knowledge, PMI, USA 2012.

[8] Cox J.F., Schleier J.G., Theory of Constraints. Handbook, McGraw-Hill Companies, US, 2010.

[9] Kastor A., Sirakoulis K., The effectiveness of resource levelling tools for resource constraint project scheduling problem, International Journal of Project Management, 27, 5, 493-500, 2009.

[10] Hall N.G., Project management: Recent developments and research opportunities, Journal of Systems Science and Systems Engineering, 21, 2, 129$143,2012$.

[11] Goldratt E.M., Critical Chain, Great Barrington, MA: North River Press, 1997.

[12] Trojanowska J., Koliński A., Kolińska K., Using of Throughout Accounting in Manufacturing Companies - case studies, Management and Production Engineering Review, 2, 1, 58-65, 2011.

[13] Trojanowska J., Pająk E., Using the Theory of Constraints to Production Processes Improvement, Proceedings of the 7th International Conference of DAAAM Baltic Industrial Engineering, Kyttner R. [Ed.], Tallin, Estonia, 1, 322-327, 2010. 
Management and Production Engineering Review

[14] Hamrol A., Strategies and practices of efficient operation. LEAN SIX SIGMA and other [in Polish], PWN, Warsaw, 2015.

[15] Simşita Z.T., Sebla Günayb N.S., Vayvayc Ö., Theory of Constraints: a Literature Review, 10th International Strategic Management Conference 2014, Procedia - Social and Behavioral Sciences, 150, 930936, 2014.

[16] Dettmer H.W., Goldratt's Theory of Constraints: a Systems Approach to Continuous Improvement, ASQ Quality Press, Milwaukee, WS, 1997.

[17] Goldratt E.M., Cox J., The Goal: Excellence In Manufacturing, North River Press, New York, 1984.

[18] Dugdale D., Jones C.T., Throughput Accounting: Transforming Practices?, The British Accounting Review, 30, 3, 203-220, 1998.

[19] Woeppel M.J., The manufacturer's guide to implementing the theory of constraints, St. Lucie Press, Boca Raton, Florida, 2001.

[20] Cyplik P., Adamczak M., Hadaś Ł., Critical chain project management and drum-buffer-rope tools integration in construction industry - case study, LogForum, 8, 1, 29-37, 2012.

[21] Goldratt E.M., The Goldratt Webcast Series: Critical Chain Project Management, Roelofarendsveen, The Netherlands: Goldratt Marketing Group, 2008.

[22] Watson K.J., Blackstone J.H., Gardiner S.C., The evolution of a management philosophy: the theory of constraints, Journal of Operations Management, 25, 387-402, 2007.

[23] Steyn H., Nicholas J.M., Project Management for Business, Engineering and Technology, Reed Elsevier India private limited, pp. 240-269, 2008.

[24] Ravalji J.M., Deshpande V.A., Comparative Study of Alternatives for 50\% Rule in Critical Chain Project Management, Vivek A Deshpande, International Conference on Design, Manufacturing and Mechatronics Organized by KJEI's Trinity College of Engineering and Research, Pune, 9-10 January, 2014.

[25] Rozenes S., Vitner G., Spraggett S., Project control: Literature review, Project Management Journal, 37, 4, 5-14, 2006.

[26] Patrick F.S., Critical chain scheduling and buffer management: getting out from between Parkinson's rock and Murphy's hard place, pp. 1-6, 1998, http://www.focusedperformance.com/articles/ ccpm.html, accessed July 31, 2016.

[27] Goldratt E.M., Eshkoli I., BrownLeer J., Isn't It Obvious?, Revised Edition, The North River Press, USA, 2009.

[28] Geekie A., Steyn H., Buffer sizing for the critical chain Project management metod, The South
African Journal of Industrial Engineering, 19, 1, 7388, 2008.

[29] Leach L.P., Critical chain project management, 2nd edition, Artech House, Inc., Norwood MA, 2005.

[30] Łopatowska J., Application of the Theory of Constraints to scheduling tasks in single and multiproject environment [in Polish], Logistyka, 2, 1-15, 2009.

[31] Arrais-Castro A., Varela M., Putnik G., Ribeiro R., Dargam F., Collaborative negotiation platform using a dynamic multi-criteria decision model, International Journal of Decision Support System Technology, 7, 1, 1-14, 2015, DOI: 10.4018/ijdsst.2015010101.

[32] Diering M., Hamrol A., Kujawińska A., Measurement system analysis Combined with Shewhart's Approach, Key Engineering Materials, Vol. 637, pp. 7-11, 2015, (c)Trans Tech Publications, Switzerland, DOI: 10.4028/www.scientific.net/KEM.637.7.

[33] Kujawińska A., Rogalewicz M., Diering M., Application of expectation maximization method for purchase decision-making support in welding branch, Management and Production Engineering Review, 7, 2, 29-33, 2016, DOI: 10.1515/mper-2016-0014.

[34] Kujawińska A., Rogalewicz M., Diering M., Hamrol A., Statistical Approach to Making Decisions in Manufacturing Process of Floorboard, [in:] Rocha Á., Correia A., Adeli H., Reis L., Costanzo S. [Eds.], Recent Advances in Information Systems and Technologies. WorldCIST, Advances in Intelligent Systems and Computing, Springer, 571, 499-508, 2017.

[35] Bożek M., Kujawińska A., Rogalewicz M., Diering M., Gościniak P., Hamrol A., Improvement of catheter quality inspection process, MATEC Web of Conferences 121, 05002, 2017, 8th International Conference on Manufacturing Science and Education - Trends in New Industrial Revolution, DOI: https://doi.org/10.1051/matecconf/201712105002.

[36] Leão C.P., Soares F.O., Machado J.M., Seabra E., Rodrigues H., Design and development of an industrial network laboratory, International Journal of Emerging Technologies in Learning (Special Issue) 6, 2, 21-26, 2011, DOI: 10.3991/ijet.v6iS1.1615.

[37] Silva M., Pereira F., Soares F., Leão C.P., Machado J., Carvalho V., An overview of industrial communication networks, Mechanisms and Machine Science, 24, 933-940, 2015, DOI: 10.1007/978-3-319-094113_97.

[38] Vieira G., Varela M., Putnik G., Machado J., An integrated framework for supporting fuzzy decisionmaking in networked manufacturing environments, Romanian Review Precision Mechanics, Optics and Mechatronics, 48, 85-91, 2015. 